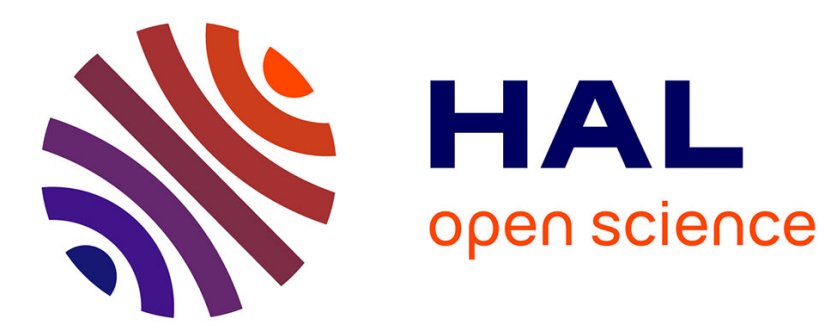

\title{
Incomplete markets and the output-inflation tradeoff
}

Yann Algan, Edouard Challe, Xavier Ragot

\section{To cite this version:}

Yann Algan, Edouard Challe, Xavier Ragot. Incomplete markets and the output-inflation tradeoff.

2008. halshs-00589134

\section{HAL Id: halshs-00589134 \\ https://shs.hal.science/halshs-00589134}

Preprint submitted on 27 Apr 2011

HAL is a multi-disciplinary open access archive for the deposit and dissemination of scientific research documents, whether they are published or not. The documents may come from teaching and research institutions in France or abroad, or from public or private research centers.
L'archive ouverte pluridisciplinaire HAL, est destinée au dépôt et à la diffusion de documents scientifiques de niveau recherche, publiés ou non, émanant des établissements d'enseignement et de recherche français ou étrangers, des laboratoires publics ou privés. 


\section{PARIS-Jourdan ScIENCES ECONOMIQUeS \\ 48, BD JOURDAN - E.N.S. - 75014 PARIS \\ TEL. : 33(0) 143136300 - FAX : $33(0) 143136310$ \\ www.pse.ens.fr}

WORKING PAPER Nº 2006 - 45

Incomplete markets and the output-inflation tradeoff

Yann Algan

Edouard Challe

Xavier Ragot

JEL Codes : E24, E31, E32

Keywords : Incomplete market, borrowing constraints, short-run nonneutrality 


\title{
Incomplete Markets and the Output-Inflation Tradeoff*
}

\author{
Yann Algan $^{\dagger} \quad$ Edouard Challe ${ }^{\ddagger} \quad$ Xavier Ragot $^{\S}$ \\ March 2008 (First version: December 2006)
}

\begin{abstract}
This paper analyses the effects of money shocks on macroeconomic aggregates in a flexible-price, incomplete-markets environment that generates persistent wealth inequalities amongst agents. In this framework, unexpected money shocks redistribute wealth from the cash-rich employed to the cash-poor unemployed, and induce the former to increase their labour supply in order to maintain their desired levels of consumption and precautionary savings. The reduced-form dynamics of the model is a textbook 'output-inflation tradeoff' equation whereby inflation shocks raise current output. The attenuating role of mean inflation and money growth persistence on this non-neutrality tradeoff, as well as some of the welfare implications of wealth redistribution, are also examined.
\end{abstract}

Keywords: Incomplete markets; borrowing constraints; short-run non-neutrality.

JEL codes: E24; E31; E32.

${ }^{*}$ We are particularly grateful to Chris Carroll, Jean-Michel Grandmont, Guy Laroque, Etienne Lehman and Victor Rios-Rull for their suggestions on an earlier version of this paper. We also received helpful comments from seminar participants at CREST-INSEE and participants at the 2007 T2M Conference (Paris) and the 2007 EEA-ESEM meeting (Budapest). Financial support from the French National Research Agency (ANR) is gratefully acknowledged. All remaining errors are ours.

${ }^{\dagger}$ Paris East University and Paris School of Economics, 48 Boulevard Jourdan, 75014 Paris, France; yann.algan@ens.fr.

${ }^{\ddagger}$ CNRS-DRM and Université Paris-Dauphine, F-75016 Paris, France; edouard.challe@dauphine.fr.

§Paris School of Economics, 48 Boulevard Jourdan, 75014 Paris, France; ragot@pse.ens.fr. 


\section{Introduction}

This paper analyses the effects of money shocks on macroeconomic variables within a flexibleprice, incomplete-markets environment that generates persistent wealth inequalities amongst agents. More specifically, we explore the aggregate and welfare effects of unexpected monetary injections in a Bewley-type model where money serves as a short-run store of value allowing agents to self-insure against idiosyncratic income fluctuations. As was first shown by Bewley $(1980,1983)$, and further analysed in a number of contributions including Kehoe et al. (1992), Imrohoroglu (1992), and Akyol (2004), this role for money arises naturally in environments where insurance markets are missing and agents cannot borrow against future income. We draw on this literature by emphasising the role of money as a buffer stock against labour-income fluctuations, where money partly substitutes for the lack of insurance and credit markets. Unlike the existing literature, however, we analyse the short-run impact of inflation shocks on output, rather than focusing on the long-run effect of steady-state inflation.

A distinguishing feature of Bewley models (relative to complete markets models) is that cash holdings are heterogenous across agents in equilibrium, because the money wealth accumulated by every single agent depends on the sequence of idiosyncratic shocks that each agent has faced. With such unequal cash holdings, lump-sum money injections that raise the price level lower the value of previously-accumulated balances and redistribute money wealth from relatively cash-rich agents, who pay the inflation tax, towards poorer agents, who benefit from the corresponding inflation subsidy. Without aggregate shocks, the redistributive effect of (fully anticipated) inflation can help households to self-insure against idiosyncratic shocks and thereby justifies mean inflation rates strictly higher than those prescribed by the so-called 'Friedman rule' (e.g., Kehoe et al, 1992; Akyol, 2004). ${ }^{1}$ In the present paper, we explore the aggregate implications of unexpected, but possibly persistent, monetary injections. Thus, our paper explores the non-neutrality of money implied by wealth redistribution within a framework combining both idiosyncratic and aggregate uncertainty about agents' incomes.

\footnotetext{
${ }^{1}$ The Friedman rule states that the inflation rate should be set so as to bring the nominal interest rate on bonds down to zero (Friedman, 1969). It has been shown to hold in a variety of monetary models with representative agents (see Woodford, 1990, for a survey).
} 
In our model, idiosyncratic income risk is rooted in the transitions of individual households between 'employment', a status where they can freely choose the labour supply they rent out to competitive firms, and 'unemployment', where households receive a fixed subsidy lower than equilibrium wage income. One central implication of our analysis is that aggregate monetary shocks generate a traditional 'output-inflation tradeoff', whereby inflation shocks contemporaneously raise employed households' labour supply and thus output. In our economy, the inflation tax redistributes real wealth from the employed, who are unconstrained and hold positive cash holdings at the beginning of the period, towards the unemployed, who are borrowing-constrained at the start of the period and thus initially hold no cash. This redistribution from unconstrained to constrained households forces the former to increase their labour supply to replete their money wealth and maintain their desired levels of consumption and money holdings. The implied increase in hours then raises current output, generating an output-inflation tradeoff whose underlying mechanism differs from traditional ones such as those based on sticky prices (e.g., Ball et al., 1988) or imperfect information (see Lucas, 1973).

What does the size of this monetary non-neutrality depend on? In our model, the redistributive effect of an inflation shock is positively related to the gap between the real balances of cash-rich and cash-poor agents, i.e., the degree of inequality in the distribution of money holdings. Higher inflation, inasmuch as it reduces the attractiveness of real balances as a means of self insurance, deters employed households from accumulating these balances and thus diminishes both money wealth inequalities and the implied impact of inflation shocks. Highly-persistent money growth shocks, to the extent that they forecast greater inflation taxes on future real balances, transitorily lower real money demand and induce a negative effect of money growth shocks on labour supply and output. The output effects of monetary shocks are thus larger when both the mean and the persistence of money growth are low. In the extreme opposite situation where both are very large, the intertemporal effects on future inflation taxes may even dominate the intratemporal, redistributive effect of the current inflation tax, and lead to a reversal in the sign of the tradeoff.

Our analysis follows the route opened by Bewley (1980), Scheinkman and Weiss (1986) and Kehoe et al. (1992). Bewley and Kehoe et al. focused on the optimal long-run inflation rate and did not analyse the short-run non-neutrality of money under incomplete markets. 
Scheinkman and Weiss were the first to identify the non-neutrality of money shocks when borrowing constraints make cash holdings heterogenous; however, the infinite-dimensional wealth distribution of their model did not allow them to derive the output-inflation tradeoff, let alone relate its size to the underlying deep parameters of the model such as mean inflation, money growth persistence, or the number of borrowing-constrained agents in the economy. Given the lack of tractability of heterogenous-agent models with infinite-state wealth distributions, an alternative approach to the one we follow is to solve them computationally. However, computational limitations have thus far limited the applicability of these models to the study of optimal steady-state inflation, again leaving aside the analysis of the short-run effects of inflation shocks (e.g., Imrohoroglu, 1992, and Akyol, 2004). We circumvent this difficulty by deriving a closed-form solution to our incomplete-markets model that generates a finite-state wealth distribution and a finite number of agent types.

Finally, the non-neutrality of inflation shocks working through wealth redistribution has recently been explored in frameworks different from Bewley models but which also generate heterogenous wealth levels across agents in equilibrium. Within the overlapping generations tradition, Doepke and Schneider (2006) look at the aggregate effects of inter-cohort redistribution from old retirees to young workers, and find a negative effect of inflation shocks on output in the short and medium run; in contrast, our model can generate a positive short-run relation between inflation and output due to intra-cohort wealth redistribution. Berentsen et al. (2005) study the effects of non-persistent money supply shocks in a search-theoretic monetary model; besides being based on a very different set of assumptions, our framework can handle auto-correlated shocks and thus assess the joint effects of current and expected inflation taxes on aggregate outcomes.

The remainder of the paper is organised as follows. Section 2 introduces the model and spells out its optimality and market-clearing conditions. Section 3 derives a closed-form equilibrium with two possible levels of real money holdings and four types of agents. Section 4 analyses the properties of the short-run output-inflation tradeoff generated by the model, paying particular attention to the role of mean inflation and the persistence of shocks in affecting the slope of the tradeoff. Section 5 concludes. 


\section{The model}

The economy is populated by a large number of firms, as well as a unit mass of infinitelylived households $i \in[0,1]$, all interacting in perfectly-competitive labour and goods markets. Firms produce output, $y_{t}$, from labour input, $l_{t}$, using the CRS technology $y_{t}=l_{t}$; they thus adjust labour demand up to the point where the real wage is equal to 1. Households' behaviour, on the other hand is potentially affected by both the (uninsurable) idiosyncratic income uncertainty that they face and the aggregate shock.

\subsection{Uncertainty}

Individual states. In every period, each household can be either employed or unemployed. We denote by $\chi_{t}^{i}$ the status of household $i$ at date $t$, where $\chi_{t}^{i}=1$ if the household is employed and $\chi_{t}^{i}=0$ if the household is unemployed. Households switch randomly between these two states, with $\alpha=\operatorname{Pr}\left(\chi_{t+1}^{i}=1 \mid \chi_{t}^{i}=1\right)$ and $\rho=\operatorname{Pr}\left(\chi_{t+1}^{i}=0 \mid \chi_{t}^{i}=0\right),(\alpha, \rho) \in(0,1)^{2}$, being the probabilities of staying employed and unemployed, respectively. Given this Markov chain for individual states, the asymptotic unemployment rate is:

$$
U=(1-\alpha) /(2-\alpha-\rho) .
$$

The history of individual shocks up to date $t$ is denoted $e_{i}^{t}$, where $e_{i}^{t}=\left\{\chi_{0}^{i}, . ., \chi_{t}^{i}\right\}$. $E^{t}=\{0,1\} \times . .\{0,1\}$ is the set of all possible histories up to date $t$, and $\mu_{t}^{i}: E^{t} \rightarrow[0,1], t=$ $0,1, \ldots$ denotes the probability measure of individual histories (for example, $\mu_{t}^{i}\left(e_{t}^{i}\right)$ is the probability of individual history $e_{t}^{i}$ for agent $i$ at date $t$ ). Following convention, we use the notation $e_{t+1}^{i} \succeq e_{t}^{i}$ to indicate that $e_{t+1}^{i}$ is a possible continuation of $e_{t}^{i}$. Finally, we limit the ability of households to diversify this idiosyncratic unemployment risk away by assuming that it is uninsurable and that agents cannot borrow against future labour income.

Aggregate states. Money growth shocks are the only source of economy-wide uncertainty that we consider. The history of these shocks up to date $t$ is denoted $h_{t}$, while $H^{t}$ is the set of all possible histories for these shocks up to date $t$. Let $\nu$ denote the probability measure over histories up to date $t: \nu_{t}: H^{t} \rightarrow[0,1], t=0,1, \ldots$ As before, $\nu_{t}\left(h_{t}\right)$ denotes the probability of history $h_{t}$ and $h_{t+1} \succeq h_{t}$ indicates that $h_{t+1}$ is a possible continuation of $h_{t}$.

In every period, a real amount $\gamma_{t}\left(h_{t}\right)>0$ of newly-issued fiat money is given symmetrically to all households by the monetary authorities (we show below how the latter is 
related to money growth, $\left.\tau_{t}\left(h_{t}\right)\right) .^{2}$ Moreover, in equilibrium the price level and the inflation rate are functions of the history of aggregate states. These are denoted $P_{t}\left(h_{t}\right)$ and $\pi_{t}\left(h_{t}\right) \equiv P_{t}\left(h_{t}\right) / P_{t-1}\left(h_{t-1}\right)-1$, respectively.

\subsection{Households' behaviour}

The household's instantaneous utility function is $u(c)-\phi l$, where $c$ is consumption, $l$ is labour supply, $\phi>0$ a scale parameter, and where $u$ is a $C^{2}$ function satisfying $u^{\prime}(c)>0$, $u^{\prime \prime}(c)<0$ and $\sigma(c) \equiv-c u^{\prime \prime}(c) / u^{\prime}(c) \leq 1 \forall c \geq 0$ (i.e. consumption and leisure are not gross complements). Fiat money is the only outside asset available and, since private borrowing is prohibited, the only asset that households can use to smooth consumption. Employed households (i.e. those for whom $\chi_{t}^{i}=1$ ) choose their labour supply, $l_{t}^{i}$, at the current wage rate $(=1)$, while unemployed households (i.e., for whom $\chi_{t}^{i}=0$ ) earn no labour income but a fixed amount of 'home production', $\delta>0 .{ }^{3}$ Let $M_{t}^{i}$ denote the nominal money holdings of household $i$ at the end of date $t$, and $m_{t}^{i} \equiv M_{t}^{i} / P_{t}$ the corresponding real money holdings (by convention, we denote by $M_{-1}^{i}$ the nominal money holdings of household $i$ at the beginning of date 0 ). Household $i$ 's problem is to choose the sequences of functions

$$
\left.\begin{array}{c}
c_{t}^{i}: H^{t} \times E^{t} \rightarrow R_{+} \\
l_{t}^{i}: H^{t} \times E^{t} \rightarrow R_{+} \\
m_{t}^{i}: H^{t} \times E^{t} \rightarrow R_{+}
\end{array}\right\} t=0,1, \ldots
$$

to maximise

$$
\sum_{t=0}^{\infty} \beta^{t} \sum_{h_{t} \in H^{t}} \nu_{t}\left(h_{t}\right) \sum_{e_{t}^{i} \in E^{t}} \mu_{t}^{i}\left(e_{t}^{i}\right)\left(u\left(c_{t}^{i}\left(h_{t}, e_{t}^{i}\right)\right)-\phi l_{t}^{i}\left(h_{t}, e_{t}^{i}\right)\right)
$$

\footnotetext{
${ }^{2}$ Our assumption that tranfers are symmetric and lump sum follows much of the litereature on Bewley models (e.g., Scheinkman and Weiss, 1986; Kehoe et al., 1992; Imrohoroglu, 1992). It can be justified on the grounds that monetary authorities are not sufficiently well informed to treat individual agents differently, as is discussed in Kehoe et al. (1992) and Levine (1991).

${ }^{3}$ Alternatively, $\delta$ can be interpreted as an unemployment subsidy financed through a compulsory lumpsum contribution, $e=U \delta /(1-U)$, paid by all employed households and ensuring the equilibrium of the unemployment insurance scheme in the steady state. In this case, steady-state labour supply and output are higher than under the home production interpretation (as working households attempt to offset the wealth effect of the unemployment contribution), but the dynamic behaviour of the economy faced with aggregate uncertainty is unchanged.
} 
where $\beta \in(0,1)$ is the discount factor, subject to

$$
\begin{gathered}
P_{t} c_{t}^{i}\left(h_{t}, e_{t}^{i}\right)+M_{t}^{i}\left(h_{t}, e_{t}^{i}\right)=M_{t-1}^{i}\left(h_{t-1}, e_{t-1}^{i}\right)+P_{t}\left(\chi_{t}^{i} l_{t}^{i}\left(h_{t}, e_{t}^{i}\right)+\left(1-\chi_{t}^{i}\right) \delta+\gamma_{t}\left(h_{t}\right)\right) \\
c_{t}^{i}\left(h_{t}, e_{t}^{i}\right), l_{t}^{i}\left(h_{t}, e_{t}^{i}\right), M_{t}^{i}\left(h_{t}, e_{t}^{i}\right) \geq 0
\end{gathered}
$$

Equation (2) is the nominal budget constraint of household $i$ at date $t$, while the last inequality in (3) indicates that agents cannot have negative asset holdings. The Lagrangian function associated with household $i$ 's problem, formulated in real terms, is: ${ }^{4}$

$$
\begin{aligned}
& L=\sum_{t=0}^{\infty} \beta^{t} \sum_{h_{t} \in H^{t}} \nu_{t}\left(h_{t}\right) \sum_{e_{t}^{i} \in E^{t}} \mu_{t}\left(e_{t}^{i}\right) \times \\
& u\left(c_{t}^{i}\left(h_{t}, e_{t}^{i}\right)\right)-\phi l_{t}^{i}\left(h_{t}, e_{t}^{i}\right)+\varphi_{t}^{i}\left(h_{t}, e_{t}^{i}\right) m_{t}^{i}\left(h_{t}, e_{t}^{i}\right) \\
& {\left[\begin{array}{c}
+\eta_{t}^{i}\left(h_{t}, e_{t}^{i}\right)\left(\frac{m_{t-1}^{i}\left(h_{t-1}, e_{t-1}^{i}\right)}{1+\pi_{t}\left(h_{t}\right)}+\chi_{t}^{i} l_{t}^{i}\left(h_{t}, e_{t}^{i}\right)+\left(1-\chi_{t}^{i}\right) \delta+\gamma_{t}\left(h_{t}\right)-c_{t}^{i}\left(h_{t}, e_{t}^{i}\right)-m_{t}^{i}\left(h_{t}, e_{t}^{i}\right)\right)
\end{array}\right],}
\end{aligned}
$$

where the Lagrange multipliers $\eta_{t}^{i}$ and $\varphi_{t}^{i}$ are positive functions defined over $H^{t} \times E^{t}$ (we check below that the non-negativity constraints on $c_{t}^{i}$ and $l_{t}^{i}$ are always satisfied in the equilibrium under consideration). From the Kuhn-Tucker theorem, the optimality conditions are, for $t=0,1, \ldots$ and for all $\left(h_{t}, e_{t}^{i}\right) \in H^{t} \times E^{t}$,

$$
\begin{gathered}
u^{\prime}\left(c_{t}^{i}\left(h_{t}, e_{t}^{i}\right)\right)=\eta_{t}^{i}\left(h_{t}, e_{t}^{i}\right), \\
\eta_{t}^{i}\left(h_{t}, e_{t}^{i}\right)=\phi \text { if } \chi_{t}^{i}=1 \text { and } l_{t}^{i}\left(h_{t}, e_{t}^{i}\right)=0 \text { if } \chi_{t}^{i}=0, \\
\eta_{t}^{i}\left(h_{t}, e_{t}^{i}\right)-\varphi_{t}^{i}\left(h_{t}, e_{t}^{i}\right)=\beta \sum_{h_{t+1} \succeq h_{t}} \nu_{t+1}\left(h_{t+1}\right) \sum_{e_{t+1}^{i} \succeq e_{t}^{i}} \mu_{t+1}^{i}\left(e_{t+1}^{i}\right) \frac{\eta_{t+1}^{i}\left(h_{t+1}, e_{t+1}^{i}\right)}{1+\pi_{t+1}\left(h_{t+1}\right)}, \\
\varphi_{t}\left(h_{t}, e_{t}^{i}\right) m_{t}^{i}\left(h_{t}, e_{t}^{i}\right)=0, \\
\lim _{t \rightarrow \infty} \beta^{t} u^{\prime}\left(c_{t}\left(h_{t}, e_{t}^{i}\right)\right) m_{t}^{i}\left(h_{t}, e_{t}^{i}\right)=0 .
\end{gathered}
$$

Equation (4) defines household $i$ 's marginal utility, while (5) and (6) are the intratemporal and intertemporal optimality conditions, respectively. Equation (7) states that either the borrowing constraint is binding for household $i\left(\varphi_{t}^{i}>0\right)$, implying that cash holdings are zero $\left(m_{t}^{i}=0\right)$, or the constraint is slack $\left(\varphi_{t}^{i}=0\right)$ and the household uses real balances to smooth consumption over time $\left(m_{t}^{i} \geq 0\right)$. Finally, condition (8) is a transversality condition

\footnotetext{
${ }^{4}$ As will become clear below, our choice of the Lagrangian function, rather than the Bellman equation, allows for a more transparent derivation of the equilibrium on which our analysis focuses.
} 
that will always hold along the equilibria that we will consider. Note that (6) can be written more compactly as:

$$
u^{\prime}\left(c_{t}^{i}\left(h_{t}, e_{t}^{i}\right)\right)=\beta E_{t}\left(\frac{u^{\prime}\left(c_{t+1}^{i}\left(h_{t+1}, e_{t+1}^{i}\right)\right)}{1+\pi_{t+1}\left(h_{t+1}\right)}\right)+\varphi_{t}^{i}\left(h_{t}, e_{t}^{i}\right) .
$$

\subsection{Market clearing}

Goods market. Equilibrium in the market for goods requires that, at each date and for all histories of aggregate states $h_{t} \in H^{t}$, the sum of each type of agent's consumption be equal to total production. Given the assumed production function, total production is simply the sum of individual labour supplies and home production, so that we have:

$$
\int_{0}^{1}\left(\chi_{t}^{i} l_{t}^{i}\left(h_{t}, e_{t}^{i}\right)+\left(1-\chi_{t}^{i}\right) \delta\right) d i=\int_{0}^{1} c_{t}^{i}\left(h_{t}, e_{t}^{i}\right) d i
$$

where the summation operator $\int$ is over individual households.

Money market. Let $M_{t}\left(h_{t}\right)$ denote the nominal quantity of money at date $t$, then moneymarket clearing may equally be written as:

$$
M_{t}\left(h_{t}\right)=\int_{0}^{1} M_{t}^{i}\left(h_{t}, e_{t}^{i}\right) d i
$$

Denote real money supply by $m_{t}\left(h_{t}\right) \equiv M_{t}\left(h_{t}\right) / P_{t}\left(h_{t}\right)$ and the (gross) rate of money growth by $\tau_{t}\left(h_{t}\right) \equiv M_{t}\left(h_{t}\right) / M_{t-1}\left(h_{t-1}\right)$. Then, symmetric real money injections can be written as:

$$
\gamma_{t}\left(h_{t}\right)=\frac{M_{t}\left(h_{t}\right)-M_{t-1}\left(h_{t-1}\right)}{P_{t}\left(h_{t}\right)}=\frac{m_{t-1}\left(h_{t-1}\right) \times\left(\tau_{t}\left(h_{t}\right)-1\right)}{1+\pi_{t}\left(h_{t}\right)},
$$

while the law of motion for the real quantity of money is:

$$
m_{t}\left(h_{t}\right)=\frac{m_{t-1}\left(h_{t-1}\right) \times \tau_{t}\left(h_{t}\right)}{1+\pi_{t}\left(h_{t}\right)} .
$$

An equilibrium is defined as sequences of individual consumption levels, $\left\{c_{t}^{i}\left(h_{t}, e_{t}^{i}\right)\right\}_{t=0}^{\infty}$, individual real money holdings, $\left\{m_{t}^{i}\left(h_{t}, e_{t}^{i}\right)\right\}_{t=0}^{\infty}$, individual labour supplies, $\left\{l_{t}^{i}\left(h_{t}, e_{t}^{i}\right)\right\}_{t=0}^{\infty}$, $i \in[0,1]$, and aggregate variables, $\left\{y_{t}\left(h_{t}\right), m_{t}\left(h_{t}\right), \pi_{t}\left(h_{t}\right)\right\}_{t=0}^{\infty}$, such that the optimality conditions (4)-(8) hold for every household $i$ and the goods and money markets clear, given the forcing sequence $\left\{\tau_{t}\left(h_{t}\right)\right\}_{t=0}^{\infty}$. 


\section{Equilibria with two-state wealth distributions}

In general, heterogenous-agent models such as that described above generate an infinite-state distribution of agent types, as all individual characteristics (i.e., agents' wealth and implied optimal choices) depend on the personal history of each agent. In this paper, we derive a closed-form solution of the model with a finite number of household types by considering a class of equilibria where the cross-sectional distribution of money holdings is two-state. The derivation involves three steps. First, we conjecture the general shape of the solution; second, we identify the conditions under which the hypothesised solution results; and third, we set the relevant parameters (the productivity of home production, here) in such a way that these conditions are always fulfilled along the equilibrium under consideration.

\subsection{Conjectured equilibrium}

We conjecture the existence of an equilibrium along which

$$
\varphi_{t}\left(h_{t}, e_{t}^{i}\right)=0 \text { if } \chi_{t}^{i}=1 \text { and } m_{t}^{i}\left(h_{t}, e_{t}^{i}\right)=0 \text { if } \chi_{t}^{i}=0
$$

that is, one where no employed household is borrowing-constrained (so that they all store cash to smooth consumption), while all unemployed households are borrowing-constrained (and thus hold no cash). From here on, we simplify notation by simply using the $i$-index for variables that depend on individual histories and the $t$-index for those that depend on the aggregate history.

Consider first the consumption level of an unemployed household. If this household was employed in the previous period, then from (2) and (12) their current consumption is:

$$
c_{t}^{i}=m_{t-1}^{i} /\left(1+\pi_{t}\right)+\delta+\gamma_{t}(>0)
$$

On the other hand, from (2) the consumption level of unemployed households who were already unemployed in the previous period is identical across such households and given by:

$$
c_{t}^{u u}=\gamma_{t}+\delta(>0)
$$

We now turn to employed households. From (4) and (5), their consumption level is identical across employed households and independent of aggregate history, i.e.,

$$
c^{e}=u^{\prime-1}(\phi)(>0) .
$$


From equations (9) and (12), the intertemporal optimality condition for an employed household is $\phi=\beta E_{t}\left(\eta_{t+1}^{i} /\left(1+\pi_{t+1}\right)\right)$. If this household is employed in the following period, which occurs with probability $\alpha$, then $\eta_{t+1}^{i}=\phi$ (see (5)). If the household moves into unemployment in the next period, then from (4) $\eta_{t+1}^{i}=u^{\prime}\left(c_{t+1}^{i}\right)$, where by construction $c_{t+1}^{i}$ is given by (13). The Euler equation for employed households is thus:

$$
\phi=\alpha \beta E_{t}\left(\frac{\phi}{1+\pi_{t+1}}\right)+(1-\alpha) \beta E_{t}\left(u^{\prime}\left(\frac{m_{t}^{i}}{1+\pi_{t+1}}+\delta+\gamma_{t+1}\right) \times \frac{1}{1+\pi_{t+1}}\right),
$$

which in turns implies that all employed households wish to hold the same quantity of real balances, denoted by $m_{t}^{e}$ (i.e., $\forall i \in[0,1], \chi_{t}^{i}=1 \Rightarrow m_{t}^{i}=m_{t}^{e}$ ). We may thus rewrite equation (13), giving the consumption level of unemployed households which were previously employed, as follows:

$$
c_{t}^{e u}=m_{t-1}^{e} /\left(1+\pi_{t}\right)+\delta+\gamma_{t} .
$$

The labour supplies of employed households depend on whether they were employed or not in the previous period. Using Eqs. (2) and (15) these are given by, respectively,

$$
\begin{gathered}
l_{t}^{e e}=c^{e}+m_{t}^{e}-m_{t-1}^{e} /\left(1+\pi_{t}\right)-\gamma_{t} \\
l_{t}^{u e}=c^{e}+m_{t}^{e}-\gamma_{t}
\end{gathered}
$$

In other words, when all unemployed households are borrowing-constrained and no employed household is, households can be of four different types, depending only on their current and past employment status, with their personal history before $t-1$ being irrelevant. This distributional simplification is essentially the outcome of the joint assumption that all unemployed households liquidate their asset holdings (i.e., $\chi_{t}^{i}=0 \Rightarrow m_{t}^{i}=0$ ), while all employed households choose the same levels of consumption and asset holdings thanks to linear labour disutility (i.e., $\chi_{t}^{i}=1 \Rightarrow m_{t}^{i}=m_{t}^{e}$ ). We denote these four households types $e e, e u$, ue and $u$, where the first and second letters refer to date $t-1$ and date $t$ employment states, respectively. Since our focus is on the way in which idiosyncratic unemployment risk affects self-insurance by the employed, we consider the effect of variations in $\alpha$ taking $U$ in (1) as given (the implied probability of leaving unemployment is thus $\rho=1-(1-\alpha)(1-U) / U)$. We then write the asymptotic shares of households as:

$$
\omega^{e e}=\alpha(1-U), \omega^{e u}=\omega^{u e}=(1-\alpha)(1-U), \omega^{u u}=U-(1-\alpha)(1-U),
$$


and we abstract from transitional issues regarding the distribution of household types by assuming that the economy starts at this invariant distribution.

Given the consumption and labour supply levels of each type of household, goods-market clearing now implies that:

$$
\omega^{e e} l_{t}^{e e}+\omega^{u e} l_{t}^{u e}+U \delta=(1-U) c^{e}+\omega^{e u} c_{t}^{e u}+\omega^{u u} c_{t}^{u u} .
$$

In the equilibrium under consideration, which we assume to prevail from date 0 onwards, unemployed households hold no money while all employed households hold the real quantity $m_{t}^{e}$. Money-market clearing thus requires that

$$
(1-U) m_{t}^{e}=m_{t}
$$

\subsection{Existence conditions}

The condition for the distribution just derived to be an equilibrium is that the borrowing constraint never be binding for $e e$ and $u e$ households but always be binding for both $u u$ and $e u$ households. The constraint is not binding for employed households if the latter never wish to borrow. Thus, interior solutions to (16) must always be such that:

$$
m_{t}^{e} \geq 0
$$

On the other hand, the Lagrange multiplier $\varphi_{t}^{i}$ must be positive when households are unemployed, so that from (4)-(6) we must have $\eta_{t}^{i}>\beta E_{t} \eta_{t+1}^{i} /\left(1+\pi_{t+1}\right)$. First consider u households, whose current consumption is just $\delta+\gamma_{t}$ (see (14)), and thus for whom $\eta_{t}^{i}=u^{\prime}\left(\delta+\gamma_{t}\right)$. These households remain unemployed with probability $\rho$, in which case they will also consume $\delta+\gamma_{t}$ in the following period and thus $\eta_{t+1}^{i}=u^{\prime}\left(\delta+\gamma_{t+1}\right)$. They leave unemployment with probability $1-\rho$ and will then consume $u^{\prime-1}(\phi)$ in the following period, so that $\eta_{t+1}^{i}=u^{\prime}\left(u^{\prime-1}(\phi)\right)=\phi$. Thus, $u u$ households are borrowing-constrained whenever:

$$
u^{\prime}\left(\delta+\gamma_{t}\right)>\rho \beta E_{t}\left(\frac{u^{\prime}\left(\delta+\gamma_{t+1}\right)}{1+\pi_{t+1}}\right)+(1-\rho) \beta E_{t}\left(\frac{\phi}{1+\pi_{t+1}}\right)
$$

We now turn to eu households. Their current consumption is given by Eq. (17), so that $\eta_{t}^{i}=u^{\prime}\left(m_{t-1}^{e} /\left(1+\pi_{t}\right)+\delta+\gamma_{t}\right)$, while, just like $u u$ households, they will be either $u u$ 
or $u e$ households in the following period. Thus, eu households are borrowing-constrained whenever:

$$
u^{\prime}\left(\frac{m_{t-1}^{e}}{1+\pi_{t}}+\delta+\gamma_{t}\right)>\rho \beta E_{t}\left(\frac{u^{\prime}\left(\delta+\gamma_{t+1}\right)}{1+\pi_{t+1}}\right)+(1-\rho) \beta E_{t}\left(\frac{\phi}{1+\pi_{t+1}}\right) .
$$

If (23) holds then (25) is more stringent than (24), so (25) is a sufficient condition for both $u u$ and $e u$ households to be borrowing-constrained. We show in the Appendix that when $\delta$ lies within the range $\left(\delta_{-}, \delta_{+}\right)$, where $0 \leq \delta_{-}<\delta_{+}$, then both (23) and (25) hold for all $t \geq 0$, provided that aggregate shocks have sufficiently small support. Intuitively, for our equilibrium to exist home production must be sufficiently productive to deter unemployed households from saving, whilst at the same time being sufficiently unproductive to induce positive precautionary savings by employed households.

\section{Intratemporal vs. intertemporal effects of monetary shocks and inflation taxes}

We are now in a position to derive the solution dynamics of our equilibrium with limited wealth heterogeneity. Using (10), (11), (16) and (22), we can summarise the dynamic behaviour of the economy by a single forward-looking equation, namely,

$$
m_{t}^{e}=\alpha \beta E_{t}\left(\frac{m_{t+1}^{e}}{\tau_{t+1}}\right)+\frac{(1-\alpha) \beta}{\phi} E_{t}\left(\frac{m_{t+1}^{e}}{\tau_{t+1}} u^{\prime}\left(\delta+\frac{m_{t+1}^{e}}{\tau_{t+1}}\left(U+(1-U) \tau_{t+1}\right)\right)\right) .
$$

Equation (26) determines the equilibrium dynamics of the real money balances held by employed households, $\left\{m_{t}^{e}\right\}_{t=0}^{\infty}$, as a function of the money growth sequence $\left\{\tau_{t}\right\}_{t=0}^{\infty}$. From now on, we take $\tau_{t}$ as the exogenous state variables, with the transfer $\gamma_{t}$ being endogenously determined by Eq. (10) in equilibrium. Then, our assumption that $\gamma_{t}>0$ implies that $\tau_{t}>1$ for all $t$, and we further assume that $\tau_{t}$ has small bounded support $\left[\tau_{-}, \tau_{+}\right]$, with $\tau_{-}>1$.

All equilibrium variables at date $t$ can be expressed as functions of $m_{t}^{e}$ and $\tau_{t}$ only. For example, substituting (10)-(11) and (22) into (18)-(19), we derive the following expressions for the labour supplies of employed households, depending on their specific type:

$$
l_{t}^{e e}=c^{e}+U m_{t}^{e}\left(\frac{\tau_{t}-1}{\tau_{t}}\right), l_{t}^{u e}=c^{e}+m_{t}^{e}\left(\frac{1+U\left(\tau_{t}-1\right)}{\tau_{t}}\right)
$$


where $l_{t}^{e e}, l_{t}^{u e}>0$. Similarly, substituting (10)-(11) and (22) into (14) and (17), the consumption levels of unemployed households can be expressed as:

$$
c_{t}^{e u}=\delta+m_{t}^{e}\left(\frac{U+(1-U) \tau_{t}}{\tau_{t}}\right), c_{t}^{u u}=\delta+(1-U) m_{t}^{e}\left(\frac{\tau_{t}-1}{\tau_{t}}\right) .
$$

It is apparent from equations (27)-(28) that money growth shocks can affect real variables either directly through changes in $\tau_{t}$ (inside each bracketed term), or indirectly through their potential effect on current real money demand, $m_{t}^{e}$ (as determined by equation (26)). For reasons that will become clear shortly, we refer to the former and the latter as the 'intratemporal' and 'intertemporal' effects of monetary shocks, respectively.

\subsection{Intratemporal effects}

The intratemporal effects of monetary shocks are isolated when money growth is i.i.d., in which case the current shock does not alter households' expectations about future inflation taxes. With i.i.d. aggregate shocks, the first-order approximation to equation (26) yields the following constant path for $m_{t}^{e .5}$

$$
m_{t}^{e}=m^{e}=\frac{1+\pi}{1+(1-U) \pi}\left(u^{\prime-1}\left(\frac{(1+\pi-\alpha \beta) \phi}{(1-\alpha) \beta}\right)-\delta\right)
$$

where unindexed variables denote steady-state values (all of these are summarised in the Appendix). Two properties of $m^{e}$ are worth mentioning at this stage. First, $m^{e}$ falls with $\alpha$, as lower idiosyncratic unemployment risk reduces employed households' incentives to self-insure against this risk. Second, under our maintained assumption that $\sigma(c) \leq 1, m^{e}$ falls with $\pi$ (this claim is established in the Appendix): as inflation increases, the return to holding real balances decreases and money becomes less valuable as a self-insurance device against idiosyncratic unemployment shocks.

We can now turn to the effects of i.i.d. aggregate shocks on labour supply and output. Equations (11) and (29) imply that $\pi_{t}=\tau_{t}-1$. Thus, individual labour supplies are:

$$
l_{t}^{e e}=c^{e}+m^{e}\left(\frac{U \pi_{t}}{1+\pi_{t}}\right), l_{t}^{u e}=c^{e}+m^{e}\left(\frac{1+U \pi_{t}}{1+\pi_{t}}\right) .
$$

\footnotetext{
${ }^{5}$ This can be checked by linearising $(26)$ around steady-state real balances and money growth, $\left(m^{e}, \tau\right)$, and solving the resulting equation forwards. That $\sigma(c) \leq 1$ implies that the equilibrium is unique and non-cyclical, while i.i.d shocks preclude time-variations in real balances.
} 
The latter equations summarise the redistributive effects of the current inflation tax on labour supplies. Note that $l_{t}^{e e}$ rises while $l_{t}^{u e}$ falls as $\pi_{t}$ increases, following households' adjustments to the intratemporal wealth redistribution generated by inflation. After an inflation shock, the households who pay the inflation tax in period $t$ are those who hold money at the beginning of period $t$ (ee and $e u$ households), while the households who benefit from the corresponding inflation subsidy are those who do not hold money at the beginning of period $t$ ( $u e$ and $u$ households). Consequently, ee households are hurt by the shock and increase their labour supply to maintain their desired levels of consumption and money wealth, while ue households can afford to work less than they would have done had the shock not occurred. From equations (20) and (30), market output, $\omega^{e e} l_{t}^{e e}+\omega^{u e} l_{t}^{u e}$, is given by:

$$
y_{t}=(1-U) c^{e}+(1-U) m^{e}\left(\frac{U \pi_{t}+1-\alpha}{1+\pi_{t}}\right) .
$$

Market output increases with current inflation (i.e. greater labour supply by ee households dominates the lower supply of $u e$ households) provided that $U+\alpha>1$, or, equivalently from (1), that $\alpha+\rho>1$ (that is, the average persistence in employment status must be sufficiently high, as we discuss further below). For small shocks, equation (31) can be approximated by the following linear 'ouput-inflation tradeoff' relation:

$$
y_{t}=y+\mu\left(\pi_{t}-\pi\right),
$$

where

$$
\mu=\frac{U+\alpha-1}{(1+\pi)(1+(1-U) \pi)}\left(u^{\prime-1}\left(\frac{(1+\pi-\alpha \beta) \phi}{(1-\alpha) \beta}\right)-\delta\right)
$$

This tradeoff equation is reminiscent of those derived by Lucas (1973) or Ball et al. (1988); the underlying mechanism that we emphasise here works very differently, however. In Lucas, agents raise production after an inflationary money shock because they cannot fully disentangle changes in relative prices from variations in the general price level; in Ball et al., the output-inflation tradeoff arises naturally from nominal rigidities. In contrast, our model features perfect information, fully-flexible prices, but heterogenous cash balances. Consequently, lump-sum monetary injections redistribute wealth from cash-rich to cashpoor households, thereby inducing employed households to alter their labour supplies in order to offset the implied wealth effects. Interestingly, the model predicts that higher trend inflation lowers the impact of inflation shocks on output (i.e., $\partial \mu / \partial \pi<0$ ), because it lowers 
money holdings by employed households and thus mitigates the redistributive effects of these shocks. We may thus conclude that this negative relation is perfectly compatible with price flexibility, contrary to the claim in Ball et al. (1988) that it supports the hypothesis of nominal rigidities.

We summarise the results obtained so far in the following proposition:

Proposition 1. Steady-state real money holdings by employed households, $m^{e}$, increase with idiosyncratic unemployment risk, $1-\alpha$, and decrease with mean inflation, $\pi$. With i.i.d. money-growth shocks, a necessary and sufficient condition for shocks to raise current output is $U+\alpha>1$ (or, equivalently, $\alpha+\rho>1$ ), while the effect of the shock on output is stronger the lower is mean inflation.

Should we expect the NSC stated in the proposition to hold empirically? Estimating transition rates between employment and unemployment from the U.S. Panel Study of Income Dynamics over the period 1984-1987, Engen and Gruber (2001, Appendix A) find $\alpha=0.97$ and $\rho=0.35$ at quarterly frequency (so that $\alpha+\rho=1.32>1$ ). Constructing annual job-loss probabilities from the Current Population Survey, Carrol et al. (2003) find a value for the average household of 0.02 (that is, $\alpha=0.98$ ). Given the unemployment rates at these dates, this unambiguously gives $\alpha+\rho>1$ at an annual frequency, and by implication at quarterly frequency. Finally, although we literally refered to $U$ and $\alpha$ as the unemployment rate and the probability of staying employed, respectively, in the context of our equilibrium these are also the share of borrowing-constrained households in the economy and the probability of becoming borrowing-constrained. The conventional estimate for the share of borrowingconstrained households in the U.S. population is 0.2 (e.g., Jappelli, 1990). Although there is no available estimate for the probability of becoming borrowing constrained (conditional on not being so), the unconditional probability of being constrained is strongly negatively correlated with both income and wealth (see Jappelli, 1990, Figures I and II). Thus, $\alpha$ should be related to the conditional probability distribution of falls in income or wealth $(1-\alpha$ is, strictly speaking, the probability that the income or wealth of an unconstrained household will fall so much in the next period that it will render this household constrained). Here again, a value of $\alpha$ below 0.8 does not seem realistic at a quarterly frequency, suggesting that the condition $U+\alpha>1$ also holds under this interpretation. 


\subsection{Intertemporal effects}

Central to the transmission of monetary shocks here is the rôle, and determinants, of the real money holdings held by the employed as a buffer against idiosyncratic unemployment risk. Under i.i.d money growth shocks, these holdings are constant over time as they are immediately and entirely repleted by employed households (through variations in labour supply) following a shock that redistributes current wealth. Obviously, this simple adjustment to exogenous disturbances is complicated if real money demand is itself affected by the current shock, which is precisely what occurs when money growth shocks display persistence. To further examine the effect of auto-correlated aggregate shocks, assume that money growth obeys the following $\mathrm{AR}(1)$ process:

$$
\tau_{t}=(1-\chi) \tau+\chi \tau_{t-1}+\epsilon_{t}
$$

where $\chi \in(0,1)$ and $\left\{\epsilon_{t}\right\}_{t=0}^{\infty}$ is a white-noise process with zero mean and small bounded support. Linearising (26) around the steady state, we obtain:

$$
\hat{m}_{t}^{e}=A E_{t}\left(\hat{m}_{t+1}^{e}\right)-B E_{t}\left(\hat{\tau}_{t+1}\right)
$$

where the hatted values denote proportional deviations from steady state (e.g., $\hat{m}_{t}^{e}=$ $\left.\left(m_{t}^{e}-m^{e}\right) / m^{e}\right)$ and $A$ and $B$ are the following constants:

$$
\begin{gathered}
A=1-\frac{(1+\pi-\alpha \beta)\left(1-\delta / c^{e u}\right) \sigma\left(c^{e u}\right)}{1+\pi} \in(0,1) \\
B=1-\frac{(1+\pi-\alpha \beta)\left(1-\delta / c^{e u}\right) \sigma\left(c^{e u}\right)}{1+\pi}\left(\frac{U}{1+(1-U) \pi}\right) \in(A, 1) .
\end{gathered}
$$

Then, iterating (35) forwards under the transversality condition (8), and using (34), gives:

$$
\hat{m}_{t}^{e}=-\left(\frac{B \chi}{1-A \chi}\right) \hat{\tau}_{t}
$$

where $B \chi /(1-A \chi)>0$. Equation (36) summarises the effect of current money growth on current real balances working through changes in future money growth (both relative to the steady state). With autocorrelated shocks, a relatively high current inflation tax on employed households forecasts high future inflation taxes, thereby lowering the desirability of money as a means of self-insurance and reducing households' incentives to supply labour to acquire it. To see how such money demand adjustments alter the response of market 
output to monetary shocks, use equations (10), (22) and (18)-(19) again to write (31) in the following slightly more general form:

$$
y_{t}=(1-U) c^{e}+(1-U) m_{t}^{e}\left(\frac{U\left(\tau_{t}-1\right)+1-\alpha}{\tau_{t}}\right) .
$$

Persistent money growth shocks lower $m_{t}^{e}$ (because of the future inflation taxes on real money), but raise $\left(U\left(\tau_{t}-1\right)+1-\alpha\right) / \tau_{t}$ provided that $U+\alpha>1$ (through contemporaneous wealth redistribution). In other words, the effect of future, expected inflation taxes on real money demand runs counter the effect induced by intratemporal wealth redistribution. Linearising equation (37) and using (36), we obtain the following results.

Proposition 2. Assume that money growth, $\tau_{t}$, follows an $\operatorname{AR}(1)$ process with autocorrelation parameter $\chi \in(0,1)$. Then, the higher is $\chi$, the lower is the impact of monetary shocks on output, while a necessary and sufficient condition for these shocks to raise output is:

$$
\frac{U+\alpha-1}{U \pi+1-\alpha}>\frac{B \chi}{1-A \chi}
$$

Whether the latter condition holds or not ultimately depends on the deep parameters that enter both sides of the inequality. When $\chi \rightarrow 0$, the analysis of the previous Section applies and monetary shocks raise current output if and only if $U+\alpha>1$. As $\chi$ rises, the intertemporal effect becomes more important and reduces the impact of shocks, possibly (but not necessarily) leading to a reversal in the sign of the tradeoff for large values of $\chi$. Finally, it is straightfoward to show that sufficiently high values of mean inflation always lead to the violation of this condition (and thus to a reversal in the tradeoff slope), as they tend to mitigate the current inflation tax (relative to future inflation taxes) following a persistent monetary shock.

Figure 1 illustrates the dynamic effects of a persistent money growth shock on monetary and aggregate supply variables (first and second row, respectively). We set $\beta=0.99, \chi=0.6$, and $\tau=1.005$ (the time period is to be interpreted as a quarter). We interpret $U$ as the share of borrowing-constrained households in the economy and set it to 0.2 (see the discussion in the previous Section). The probability of becoming borrowing constrained in the next quarter is set to $5 \%$, so that $\alpha=0.95$. The instantaneous utility function is $\ln c-l$ and the home production parameter $\delta=0.9 c^{e u}$ (these parameters ensure that the existence conditions stated in Section 3.2 are satisfied.) 
Following a persistent money growth shock, real money demand falls (due to the future inflation taxes expected by employed households), and inflation jumps up. ee-households persistently raise their labour supply to offset the inflation tax, while ue-households lower their labour supply in response to the inflation subsidy. Overall, the responses of labour supplies to the shock imply that the latter persistently raises output; this is because the labour supply response of $u e$-households, although relatively large at the individual level, is actually small in the aggregate (with $\alpha=0.95$, equation (20) implies that there are about 20 times as many $e e$-households as $u e$-households.)
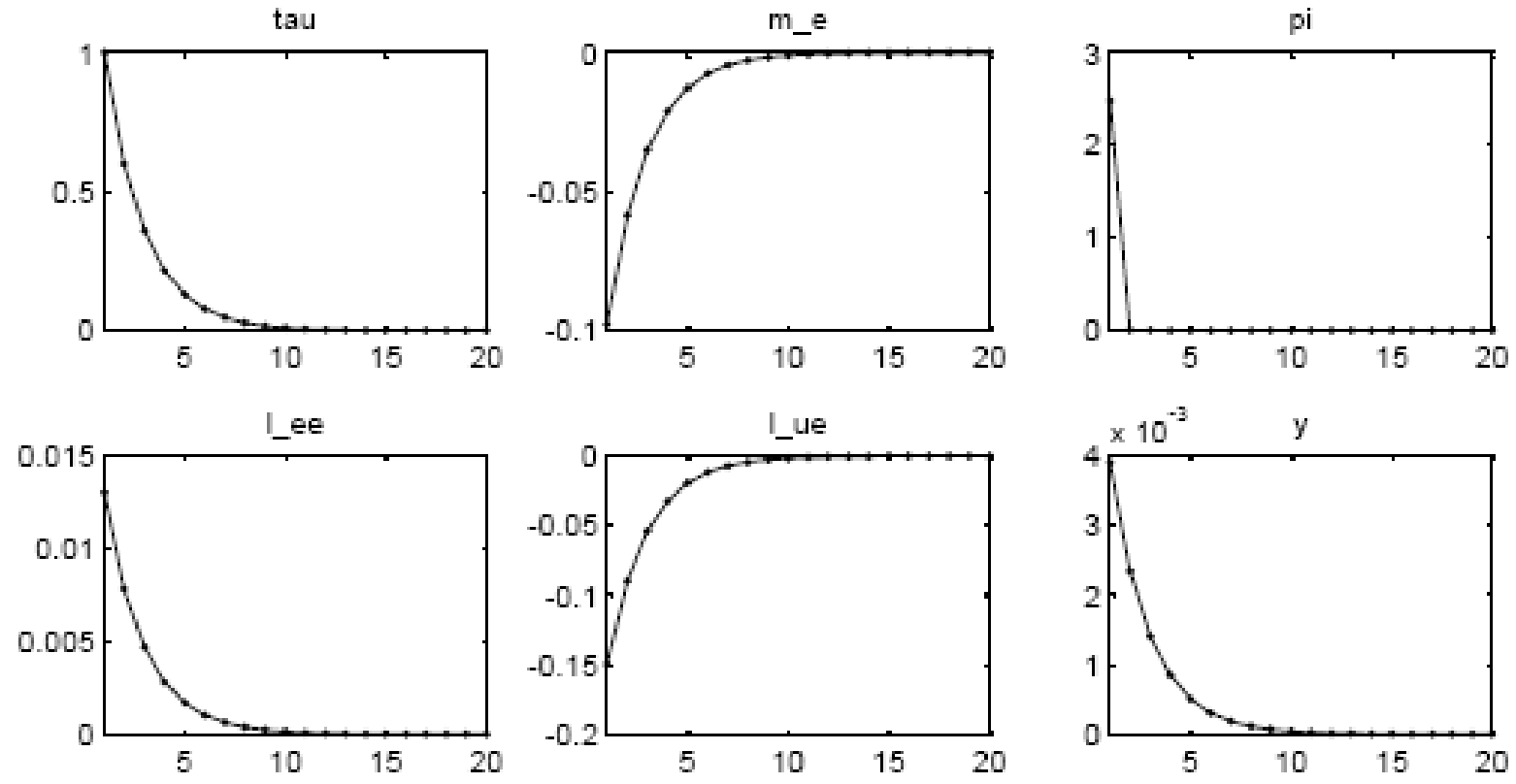

Figure 1: Level-deviations from steady state of money growth, real money demand, inflation, labour supplies and output, following a normalised, unexpected money growth innovation.

\subsection{Welfare considerations}

Since the non-neutrality mechanism described in this paper relies on wealth redistribution (both at the time of the shock and in the future), it directly affects the welfare of every single agent. Obviously, there are potential losers and winners resulting from wealth redistribution, meaning that we should not in general expect monetary shocks to unambiguously lead to better or worse dynamic equilibria in the Pareto sense.

To understand this point further, recall from (27)-(28) and (35) that all time- $t$ variables 
can be expressed as functions of the only state variable of the model, current money growth $\tau_{t}$, and that $\tau_{t+1}$ only depends on $\tau_{t}$. We focus on the dynamic and welfare effects of an once-off, unexpected aggregate shock, and call $W^{i}\left(\tau_{t}\right)$ the maximum value function of agent $i$ when current money growth is $\tau_{t}$ :

$$
\begin{aligned}
W^{i}\left(\tau_{t}\right) & =E\left(\sum_{k=0}^{\infty} \beta^{k}\left(u\left(c^{i}\left(\tau_{t+k}\right)\right)-\phi l^{i}\left(\tau_{t+k}\right)\right) \mid \chi_{t}^{i}, \tau_{t}\right) \\
& =u\left(c^{i}\left(\tau_{t}\right)\right)-\phi l^{i}\left(\tau_{t}\right)+\beta E\left(W^{i}\left(\tau_{t+1}\right) \mid \chi_{t}^{i}, \tau_{t}\right)
\end{aligned}
$$

Denote by $W_{\tau}^{i}=\partial W^{i}\left(\tau_{t}\right) /\left.\partial \tau_{t}\right|_{\tau_{t}=\tau}$ the first derivatives of this value function, evaluated at the steady state, and recall from (34) that $\partial \tau_{t+1} / \partial \tau_{t}=\chi$. Then, in the vicinity of the steady state (i.e., where $\left.\partial W^{i}\left(\tau_{t+1}\right) / \partial \tau_{t+1} \simeq \partial W^{i}\left(\tau_{t}\right) / \partial \tau_{t} \simeq W_{\tau}^{i}\right)$, and given the transition probabilities across employment status, the first derivatives of the Bellman equations associated with each agent type are related as follows:

$$
\begin{aligned}
& W_{\tau}^{e e}=-\left.\phi \frac{\partial l^{e e}\left(\tau_{t}\right)}{\partial \tau_{t}}\right|_{\tau_{t}=\tau}+\alpha \beta \chi W_{\tau}^{e e}+(1-\alpha) \beta \chi W_{\tau}^{e u}, \\
& W_{\tau}^{u e}=-\left.\phi \frac{\partial l^{u e}\left(\tau_{t}\right)}{\partial \tau_{t}}\right|_{\tau_{t}=\tau}+\alpha \beta \chi W_{\tau}^{e e}+(1-\alpha) \beta \chi W_{\tau}^{e u}, \\
& W_{\tau}^{e u}=\left.\frac{\partial u\left(c^{e u}\left(\tau_{t}\right)\right)}{\partial \tau_{t}}\right|_{\tau_{t}=\tau}+\rho \beta \chi W_{\tau}^{u u}+(1-\rho) \beta \chi W_{\tau}^{u e}, \\
& W_{\tau}^{u u}=\left.\frac{\partial u\left(c^{u u}\left(\tau_{t}\right)\right)}{\partial \tau_{t}}\right|_{\tau_{t}=\tau}+\rho \beta \chi W_{\tau}^{u u}+(1-\rho) \beta \chi W_{\tau}^{u e} .
\end{aligned}
$$

The solution to this system expresses the first derivatives of the four value functions as (cumbersome) functions of the deep parameters of the model. ${ }^{6}$ The effects of money growth shocks on the intertemporal utility of individual households can easily be computed when $\chi \rightarrow 0$ (the i.i.d. case in the limit). Then, the above system and equations (27)-(29) give:

$$
\begin{aligned}
\lim _{\chi \rightarrow 0} W_{\tau}^{e e} & =-m^{e} \phi U / \tau^{2}<0, \\
\lim _{\chi \rightarrow 0} W_{\tau}^{u e} & =m^{e} \phi(1-U) / \tau^{2}>0, \\
\lim _{\chi \rightarrow 0} W_{\tau}^{e u} & =-m^{e} U u^{\prime}\left(c^{e u}\right) / \tau^{2}<0, \\
\lim _{\chi \rightarrow 0} W_{\tau}^{u u} & =m^{e}(1-U) u^{\prime}\left(c^{u u}\right) / \tau^{2}>0 .
\end{aligned}
$$

These latter equations state that the households who benefit from the inflation subsidy at the time of the shock ( $u u$ and $u e$-households, i.e., those who hold no cash at the beginning

\footnotetext{
${ }^{6}$ More specifically, the solution to this system expresses the $W_{\tau}^{i}$ as functions of the $\partial(.) /\left.\partial \tau_{t}\right|_{\tau_{t}=\tau}$ terms, which latter can in turn be computed from equations (27)-(28) and (35)
} 
of the period) always see their utility increase, while those who pay for the inflation tax (ee and $e u$-households, who are cash-rich at the beginning of the period) necessarily experience a welfare loss. We cannot derive such clear-cut results on individuals' welfare, however, out of this limiting case, due to the combined effect of future expected redistribution and the transition of households between employment states. For example, a households which currently suffers from the inflation tax (say, a ee-household) may expect to benefit from it in the future (if, for example, $\alpha$ is low relative to $\rho$ ), making the overall welfare of this household a priori ambiguous. (Conversely, a household which currently benefits from the redistributive effect of inflation may suffer from it in the future if the probability of being being cash-rich for sufficiently many periods in the future is high).

\section{Concluding remarks}

This paper has uncovered some dynamic and welfare effects of aggregate monetary shocks in a Bewley-type monetary model with idiosyncratic labour income risk. We have shown that money-growth shocks that contemporary redistribute real money wealth across agents tend to raise output, unless this direct effect is counterbalanced by the (indirect) effect of expected future redistribution on the real demand for cash. Finally, the fact that wealth is redistributed both at the time of the shock and in the future (provided that money growth variations are persistent), combined with the perpetual transitions of households across employment status and cash-holding levels, implies that the welfare effects of monetary shocks are in general ambiguous (in the Pareto sense).

The inherent complexity of Bewley-type models with both indiosyncratic and aggregate uncertainty, which is a consequence of the very large number of agent types that these models usually generate, is notorious and may have hindered their use (see the discussion in Kehoe and Levine, 2001). Our response to this challenge has been to construct, and then to focus on, a closed-form equilibrium with a small number of wealth states and thus limited household heterogeneity. The resulting simplicity of our framework may make it useful for

the better understanding of the effects of other macroeconomic shocks (e.g., fiscal policy shocks) in incomplete-market, heterogenous-agent economies. 


\section{Appendix: Steady state of the model}

We use variables without time indices here to indicate steady-state values. From Eqs. (10)(11), steady state inflation and real transfers are $1+\pi=\tau$ and $\gamma=m \pi /(1+\pi)$, respectively (and since $\gamma_{t}>0 \forall t$ by assumption, we have that $\gamma, \pi>0$ and $\tau>1$.) Substituting these values into (16) and using (22), we find that steady-state real money holdings by employed households, $m^{e}$, are:

$$
m^{e}=\frac{1+\pi}{1+(1-U) \pi}\left(u^{\prime-1}\left(\frac{(1+\pi-\alpha \beta) \phi}{(1-\alpha) \beta}\right)-\delta\right) .
$$

The values of $c^{u u}, c^{e u}, l^{e e}, l^{u e}$ and $y$ can then be derived straightforwardly. For example,

$$
c^{e u}=u^{\prime-1}\left(\frac{(1+\pi-\alpha \beta) \phi}{(1-\alpha) \beta}\right) .
$$

Since we are considering fluctuations occurring arbitrarily close to the steady state, a sufficient condition for our closed-form solution to be an equilibrium is that both (23) and (25) hold with strict inequalities in the steady state. From (29), the first condition is simply:

$$
\delta<u^{\prime-1}\left(\frac{(1+\pi-\alpha \beta) \phi}{(1-\alpha) \beta}\right) \equiv \delta_{+} .
$$

In the steady state, the left-hand side of (25) is $c^{e u}$. Using (A1), inequality (25) becomes:

$$
\frac{(1+\pi)(1+\pi-\alpha \beta)}{(1-\alpha) \beta}-(1-\rho) \beta>\frac{\rho \beta}{\phi} u^{\prime}(\delta+\gamma) .
$$

In the steady state, $\gamma=(1-U) m^{e} \pi /(1+\pi)$ (see Eqs. (10) and (22)). Substituting $\gamma$ into (A2), using Eq. (29) and rearranging, we may rewrite the latter inequality as:

$$
\begin{aligned}
& \frac{(1+\pi)(1+\pi-\alpha \beta)}{(1-\alpha) \beta}-(1-\rho) \beta> \\
& \quad \frac{\rho \beta}{\phi} u^{\prime}\left(\frac{\delta}{1+(1-U) \pi}+\frac{(1-U) \pi}{1+(1-U) \pi} u^{\prime-1}\left(\frac{(1+\pi-\alpha \beta) \phi}{(1-\alpha) \beta}\right)\right) .
\end{aligned}
$$

The left-hand side of (A3) is positive at $\pi=0$ and thus for all $\pi>0$. The right-hand side of (A3) is decreasing and continuous in $\delta$ over $[0, \infty)$. Thus, if (A3) holds when evaluated at $\delta=\delta_{+}$, then by continuity there exists $\delta_{-}<\delta_{+}$such that (A3) holds for all $\delta>\delta_{-}$. Setting $\delta=\delta_{+}$in (A3) and rearranging, we find:

$$
(1+\pi-\rho \beta)(1+\pi-\alpha \beta)-(1-\rho)(1-\alpha) \beta^{2}>0
$$


which is always true when $\pi>0$ because the left-hand side increases with $\pi$ and is positive at $\pi=0$.

In Section 4.1 we referred to the comparative-static property that steady-state inflation decreases with mean inflation. To establish this, note that a sufficient condition for $\partial m^{e} / \partial \pi<0$ is that

$$
\frac{\partial(1+\pi) u^{\prime-1}((1+\pi-\alpha \beta) /(1-\alpha) \beta)}{\partial(1+\pi)}<0
$$

Since from $\mathrm{A} 1 u^{\prime-1}((1+\pi-\alpha \beta) \phi /(1-\alpha) \beta)=c^{e u}$, this condition may be written as:

$$
c^{e u}+(1+\pi) \phi /(1-\alpha) \beta u^{\prime \prime}\left(c^{e u}\right)<0
$$

or, after rearranging, $\sigma\left(c^{e u}\right)<(1+\pi) /(1+\pi-\alpha \beta)$. This is always true since $\sigma(c) \leq 1 \forall c$ by assumption.

\section{References}

Akyol, A. (2004), 'Optimal monetary policy in an economy with incomplete markets and idiosyncratic risk', Journal of Monetary Economics, 51, pp. 1245-1269.

Ball, L., Mankiw, N.G. and Romer D. (1988), 'The New Keynesian economics and the output-inflation trade-off', Brookings Papers on Economic Activity, 1988(1), pp. 1-82.

Berentsen, A., Camera, G. and Waller, C. (2005), 'The distribution of money balances and the nonneutrality of money', International Economic Review, 46(2), pp. 465-487.

Bewley, T. (1980), 'The optimum quantity of money'. In: Kareken, J.H., Wallace, N. (Eds.), Models of Monetary Economies. Federal Reserve Bankof Minneapolis, Minneapolis, MN. Bewley, T.F. (1983), 'A difficulty with the optimum quantity of money', Econometrica, 51(5), pp. $1485-1504$.

Carroll, C.D., Dynan, K.E. and Krane, S.D. (2003), 'Unemployment risk and precautionary wealth', Review of Economics and Statistics, 85, pp. 586-605.

Doepke, M. and Schneider, M. (2006), 'Aggregate implications of wealth redistribution: the case of inflation', Journal of the European Economic Association, 4(2-3), pp. 493-502.

Engen, I.M. and Gruber, J. (2001), 'Unemployment insurance and precautionary savings', Journal of Monetary Economics, 47, pp. 545-579. 
Friedman, M. (1969), 'The optimum quantity of money'. In: The Optimum Quantity of Money and Other Essays. Chicago: Aldine.

Imrohoroglu, A. (1992), 'The welfare cost of inflation under imperfect insurance', Journal of Economic Dynamics and Control, 16, pp.79-91.

Jappelli, T. (1990), 'Who is credit constrained in the U.S. economy?', Quarterly Journal of Economics, 105(1), pp. 219-234.

Kehoe, T.J. and Levine, D. (2001), 'Liquidity constrained markets versus debt constrained markets', Econometrica, 69(3), pp. 575-598.

Kehoe, T.J. and Levine, D. K. and Woodford, M. (1992). 'The optimum quantity of money revisited'. In: Dasgupta, P., Gale, D., Hart, O., Maskin, E. (Eds.), Economic Analysis of Markets and Games. MIT Press, Cambridge, MA.

Levine, D.K. (1991), 'Asset trading mechanisms and expansionary policy', Journal of Economic Theory, 54(1), pp. 148-164.

Lucas, Jr., R.E. (1973), 'Some international evidence on output-inflation tradeoffs', American Economic Review Vol. 63, No. 3, pp. 326-334.

Scheinkman, J.A. and Weiss, L. (1986), 'Borrowing constraints and aggregate economic activity', Econometrica, 54(1), pp. 23-45.

Woodford, M. (1990), 'The optimum quantity of money'. In: Friedman, B.M. and Woodford, M. (Eds.), Handbook of Monetary Economics, vol. II. Elsevier Science Publishers, NorthHolland, Amsterdam. 